\title{
Combination of Electroconvulsive Therapy and Clozapine in Treatment-Resistant Schizophrenia
}

\author{
Jung Hyun Kim¹, Tak Youn ${ }^{1,2}$, Jun Gwon $\mathrm{Choi}^{3}$, Seong Hoon Jeong ${ }^{4}$, \\ Hee Yeon Jung ${ }^{5,6}$, Yong Sik Kim ${ }^{1,2}$, and In Won Chung ${ }^{1,2} \bowtie$ \\ ${ }^{1}$ Department of Psychiatry \& Electroconvulsive Therapy Center, Dongguk University International Hospital, Goyang, Republic of Korea \\ ${ }^{2}$ Institute of Clinical Psychopharmacology, Dongguk University College of Medicine, Goyang, Republic of Korea \\ ${ }^{3}$ Department of Anesthesiology and Pain Medicine, Dongguk University International Hospital, Goyang, Republic of Korea \\ ${ }^{4}$ Department of Psychiatry, Eulji University Hospital, Daejeon, Republic of Korea \\ ${ }^{5}$ Department of Psychiatry, SMG-SNU Boramae Medical Center, Seoul, Republic of Korea \\ ${ }^{6}$ Department of Psychiatry and Behavioral Science and Institute of Human Behavioral Medicine, Seoul National University College of Medicine, \\ Seoul, Republic of Korea
}

Objective This study aimed to investigate the effectiveness and tolerability of the combination of electroconvulsive therapy (ECT) in patients with clozapine-treated schizophrenia.

Methods Patients with clozapine-treated schizophrenia during five years of pre-determined period were recruited from Electronic Medical Record. Clinical effects of acute ECT on psychotic symptoms were investigated. We also tried to identify predictive variables requiring maintenance treatment of ECT.

Results Fourteen patients received ECT and clozapine and sixteen were treated with clozapine alone. In the ECT group, which could be refined as clozapine-resistance, PANSS total score was significantly reduced by $19.0 \pm 9.9$ points, corresponding to a reduction rate of $18.5 \pm 8.3 \%$. The clinical remission defined as $20 \%$ PANSS reduction criteria was achieved at $42.9 \%$. The subscale factors were significantly reduced, among which the negative symptom was the least. There was no difference in demographic and clinical information between patients receiving and not receiving maintenance ECT, and not all patients seemed to need maintenance ECT if clozapine is continued.

Conclusion Combination of ECT and clozapine in patients with clozapine-resistant schizophrenia resulted in a rapid and substantial reduction of psychotic symptoms. Further studies are needed to improve the effectiveness and tolerability of ECT.

Psychiatry Investig 2018;15(8):829-835

Key Words Electroconvulsive therapy, Clozapine, Clozapine-treated schizophrenia, Clozapine-resistance, Maintenance treatment, PANSS.

\section{INTRODUCTION}

Electroconvulsive therapy (ECT) has been known as an effective and safe treatment of major psychiatric disorders since it was introduced in $1938 .^{1,2}$ Recently, ECT has received re-

\footnotetext{
Received: March 2, 2018 Revised: April 19, 2018

Accepted: May 15, 2018

$\square$ Correspondence: In Won Chung, $\mathrm{MD}, \mathrm{PhD}$

Department of Psychiatry and Electroconvulsive Therapy Center, Dongguk University International Hospital, Institute of Clinical Psychopharmacology, Dongguk University School of Medicine, 27 Dongguk-ro, Ilsandong-gu, Goyang 10326, Republic of Korea

Tel: +82-31-961-7231, Fax: +82-31-961-7236, E-mail: ciwkjs@gmail.com

(a) This is an Open Access article distributed under the terms of the Creative Commons Attribution Non-Commercial License (https://creativecommons.org/licenses/bync/4.0) which permits unrestricted non-commercial use, distribution, and reproduction in any medium, provided the original work is properly cited.
}

newed attention due to the development of ECT technology and the increasing limitations of psychotropic drugs. ${ }^{3,4}$ Moreover, high relapse rates ${ }^{5,6}$ and cognitive adverse events, ${ }^{7}$ previously presumed to be associated with ECT, have been effectively addressed through application of maintenance treatment (M-ECT), combination with psychotropic drugs, and optimization of ECT. ${ }^{8,9}$

Clozapine is known to be the most effective drug for treatment-resistant schizophrenia (TRS), a clinical-based concept with various operating criteria, ${ }^{10}$ but $40 \%$ to $70 \%$ of patients with TRS do not respond to clozapine, ${ }^{11-14}$ so called clozapineresistance. ${ }^{15}$ To overcome clozapine-resistance, a number of adjunctive approaches including pharmacological and nonpharmacological options have been attempted, but the results 
have been only modest or equivocal, ${ }^{16-20}$ except ECT augmentation with high response rates. ${ }^{21,22}$ Recent studies including case reports, ${ }^{23-25}$ open-label studies, ${ }^{8,26}$ meta-analyses, ${ }^{27-29}$ reviews, ${ }^{13,28,30,31}$ and randomized controlled trial ${ }^{22}$ demonstrated that ECT augmentation on clozapine has shown clinical improvement in $47.4-72.7 \%$ of patients with clozapine-resistant schizophrenia, ${ }^{13,26,28,32,33}$ though the majority of current reports are derived from a small number of patients and short-term observation. ${ }^{29}$ Therefore, to further ensure the efficacy of ECT augmentation in patients treated with clozapine, it is necessary to rule out possible pseudo-resistance to clozapine, ${ }^{14,17,19,22}$ such as plasma clozapine concentrations greater than $350 \mathrm{ng} /$ $\mathrm{mL}^{34}$ and a longer period of time for the clozapine response than generally recommended 4 to 6 weeks of administration to assess the acute response of other antipsychotics. $8,9,14,29,32$ And the cognitive function carried out from weeks to months after receiving ECT to track the adverse events should be evaluated. ${ }^{29,35}$ In addition, the research is required to determine whether the ECT augmentation on clozapine in Asian patients with treatment-resistant schizophrenia has the same effect over racial differences. ${ }^{8,36-38}$

An acute course of ECT is beneficial for relieving psychiatric symptoms, ${ }^{39}$ but the relapse rate is relatively high after the end of ECT, mainly reported in mood disorders. ${ }^{40,41}$ Conflicting results of ECT for the treatment of schizophrenia ${ }^{39}$ and scarce evidence regarding adjunctive option for clozapine-resistant patients ${ }^{19}$ have been reported. 1-year relapse rate was reported of $42.7-63.6 \%$ in patients with schizophrenia, mostly recurred within first 6 months. ${ }^{42,43}$ The propensity for relapse increases especially when ECT is abruptly terminated after reaching a remission. ${ }^{44}$ The maintenance treatment after acute ECT has been recommended to maintain clinical remission, prevent relapse, and improve quality of life, ${ }^{5,14,22,35,39,45,46}$ but there are no predictive clinical data such as indications, duration of treatment, etc. of patients in need of maintenance treatment.

This naturalistic observation study as an extension of our previous study ${ }^{32}$ aimed to investigate the effectiveness and tolerability of the combination of ECT and clozapine in Korean patients with treatment-resistant schizophrenia. In this study, we have increased the number of patients in order to be able to identify clinical variables associated with ECT efficacy. We explored the demographic and clinical characteristics in patients combined with ECT and clozapine in comparison with those treated with clozapine only as an open comparator. We further investigated the differences in various psychotic symptoms in response to ECT and explored the predictive variables associated with M-ECT in maintaining improved psychotic symptoms induced by acute ECT.

\section{METHODS}

\section{Subjects}

Patients who were diagnosed with schizophrenia in accordance with the DSM-IV-TR criteria, between the ages of 20 and 65 years, and treated with clozapine were identified in the electronic medical records (EMR) of Dongguk University International Hospital from March 2012 to December 2016. Patients who were treated with clozapine for at least 12 weeks and simultaneously maintained plasma clozapine levels of greater than $350 \mathrm{ng} / \mathrm{mL}$ regardless of ECT augmentation during the observation period were selected. Among the patients presented in our previous study, ${ }^{32}$ patients who met inclusion criteria were included. Patients who had comorbid physical illnesses, substance addiction, IQs less than 80 , or inadequate clinical information were excluded.

\section{Methods}

Demographic and clinical information including the history of antipsychotic treatment and ECT were collected in the EMR. The ECT augmentation on clozapine for individual patients had been determined by charged board certified psychiatrist. The reasons for the ECT recommendation were due to insufficient clinical efficacy and intolerance to current clozapine treatment. ECT for individual patients had been approved by the ad hoc committee in accordance with legal procedures prior to ECT application.

Psychotic symptoms were assessed by the Positive and Negative Syndrome Scale (PANSS). To explore the effectiveness and tolerability of ECT in patients treated with clozapine, the PANSS and daily doses and plasma levels of clozapine evaluated on the same day immediately before and after the acute course of ECT were collected. The PANSS were explored with Kay's model ${ }^{47}$ of three subscale factors such as positive symptom, negative symptom, and general psychopathology and with Tuinier's cognitive domain ${ }^{48}$ which was derived from the sum of 9 items in the PANSS. Adverse events and cognitive effects that might be caused by ECT were collected from progress notes during the observation period by MMSE-KC. This study proposal was approved by the Institutional Review Board of Dongguk University International Hospital (2015-05).

\section{ECT procedures}

As the index ECT, the acute course of ECT was performed three times a week initially, and then decreased to twice per week later according to the patient's condition. The bilateral electrode placement and brief pulse stimuli $(800 \mathrm{~mA} ; 0.5 \mathrm{~ms})$ with a MECTA spECTrum 5000Q (MECTA Corp, Lake Oswego, OR, USA) were applied. We used our own stimulus ta- 
ble which was modified from the stimulus tables of Coffey et al., ${ }^{49}$ Seoul National University Hospital (2012), and the ECT program (2015) at Western Psychiatric Institute and Clinic of the University of Pittsburgh Medical Center. To identify initial seizure threshold at the first session, an upward titration method was applied. The ECT procedure under anesthesia and muscle relaxation was described in detail in our previous report. $^{32}$

\section{Statistical analysis}

Nominal data, such as the age, duration of illness, PANSS, and clozapine data, were analyzed by paired t-test and t-test according to the comparison groups. The sex ratio and presence of family history were calculated by chi-square test. The effect sizes for the mean differences between the PANSS total and subscale scores before and after ECT were calculated to compare the degree of difference among the PANSS subscale factors using Cohen's d. ${ }^{50}$ The difference in demographic and clinical characteristics between the groups receiving M-ECT and those not was statistically determined by Mann-Whitney $\mathrm{U}$ test. Statistical significance was set at a p-value of less than 0.05. All statistical analyses were performed using SPSS ver. 23.0 for Windows (IBM Corp., Armonk, NY, USA).

\section{RESULTS}

\section{Demographic characteristics}

During five-year observation period, thirty patients were satisfied with the inclusion criteria for plasma clozapine concentrations of greater than $350 \mathrm{ng} / \mathrm{mL}$ and the duration of clozapine administration for at least 12 weeks after excluding patients who met the exclusion criteria. Among them, fourteen patients received in the ECT augmentation (ECT group) and remaining sixteen were treated with clozapine alone with no ECT (non-ECT group) (Table 1). We included seven patients presented in our previous study ${ }^{32}$ because they all met inclusion criteria. There was no significant difference in demographic characteristics and clinical information between two groups.

Among fourteen patients, thirteen were followed up until the end of pre-determined observation period of five years and one patient who stopped visiting the hospital during the observation period was excluded from the long-term follow-up. Six $(46.2 \%)$ patients continued maintenance treatment combined with clozapine and seven (53.8\%) were treated with clozapine alone with no additional ECT.

\section{Sessions and parameters of ECT}

The mean session number and duration of acute ECT were $14.9 \pm 4.6$ and $44.9 \pm 15.4$ days, respectively. The mean electrical charges were $147.4 \pm 69.7 \mathrm{mC}$ as the initial seizure threshold and $236.9 \pm 142.4 \mathrm{mC}$ at last session of acute ECT $(\mathrm{t}=2.35$, $\mathrm{p}=0.035$, by paired $\mathrm{t}$-test). The total charge and total seizure duration in average were 2,981.2 $\pm 2,029.6 \mathrm{mC}$ and 687.4 \pm 296.6 seconds, respectively. There was no gender difference based on ECT parameters.

\section{Clozapine dosages and plasma levels}

The mean clozapine dose of $367.9 \pm 125.7 \mathrm{mg}$ in the ECT group before ECT was not significantly reduced to $292.9 \pm 81.1$ mg after ECT but was statistically different from $265.6 \pm 60.5$ $\mathrm{mg}$ in the non-ECT group ( $\mathrm{t}=2.90, \mathrm{p}=0.007$ by $\mathrm{t}$-test $)$ (Table 2$)$. However, the mean clozapine dose after ECT in the ECT group was not different from that in the non-ECT group.

The mean plasma clozapine level of $628.8 \pm 182.2 \mathrm{mg}$ before

Table 1. Demographic characteristics and clinical information of the ECT and the non-ECT groups in patients with clozapine-treated schizophrenia

\begin{tabular}{|c|c|c|c|c|c|}
\hline & & ECT group $(\mathrm{N}=14)$ & Non-ECT group $(\mathrm{N}=16)$ & $\mathrm{t}\left(\chi^{2}\right)$ & $\mathrm{p}$ \\
\hline \multicolumn{2}{|l|}{ Age (yr) } & $36.6 \pm 12.5$ & $33.7 \pm 8.1$ & 0.78 & 0.445 \\
\hline \multicolumn{2}{|c|}{ Education (yr) } & $14.0 \pm 2.2$ & $14.4 \pm 2.1$ & -0.56 & 0.583 \\
\hline \multicolumn{2}{|c|}{ Sex (male, N) } & 7 & 8 & 0.00 & 1.000 \\
\hline \multicolumn{2}{|c|}{ Family history (yes, N) } & 7 & 4 & 2.01 & 0.156 \\
\hline \multicolumn{2}{|c|}{ Illness duration (yr) } & $14.3 \pm 8.1$ & $15.1 \pm 6.5$ & -0.33 & 0.745 \\
\hline \multicolumn{2}{|c|}{ Clozapine duration (yr) } & $6.0 \pm 5.2$ & $6.8 \pm 4.7$ & -0.48 & 0.634 \\
\hline \multicolumn{6}{|l|}{ PANSS } \\
\hline \multirow[t]{4}{*}{ Kay's } & Total score & $101.7 \pm 13.9$ & $76.6 \pm 10.1$ & 5.74 & $<0.001$ \\
\hline & Positive symptom & $26.5 \pm 3.7$ & $19.9 \pm 3.8$ & 4.78 & $<0.001$ \\
\hline & Negative symptom & $26.4 \pm 7.6$ & $20.1 \pm 3.2$ & 3.07 & 0.005 \\
\hline & General psychopathology & $48.8 \pm 6.3$ & $36.6 \pm 5.6$ & 5.63 & $<0.001$ \\
\hline \multicolumn{2}{|c|}{ Tuinier's cognitive domain } & $30.1 \pm 5.7$ & $21.4 \pm 3.4$ & 5.17 & $<0.001$ \\
\hline
\end{tabular}

Numbers are mean \pm SD. t-tests and chi-square tests were conducted. PANSS: Positive And Negative Syndrome Scale, ECT: electroconvulsive therapy 
ECT was significantly decreased to $518.2 \pm 203.1 \mathrm{mg}$ after ECT ( $\mathrm{t}=-2.16, \mathrm{p}=0.049$ by paired $\mathrm{t}$-test), but both levels were not statistically different from $580.1 \pm 187.7 \mathrm{mg}$ in the non-ECT group (Table 2).

\section{PANSS changes}

The mean PANSS total score was significantly reduced from $101.7 \pm 13.9$ to $82.7 \pm 13.5$ points $(\mathrm{t}=-7.21, \mathrm{p}<0.001$ by paired t-test) which was reduced $19.0 \pm 9.9$ points in average by ECT (Table 3). The mean reduction rate was $18.5 \pm 8.3 \%$. Six (42.9\%) of fourteen patients were in clinical remission as defined by a $20 \%$ reduction in the PANSS score by 1-7 scoring system. The subscale factors adopted from the model of Kay et al. ${ }^{47}$ and Tuinier's cognitive domain showed that all factors were significantly reduced by the index ECT, among which the negative symptom was the least. The effect sizes of the mean difference between before and after ECT were -1.213 for PANSS total score, -1.598 for positive symptom, -0.548 for negative symptom, -1.579 for general psychopathology, and -0.991 for Tuinier's cognitive domain.

The mean PANSS total score before ECT was also significantly different from $76.6 \pm 10.1$ points in the non-ECT group $(\mathrm{t}=5.74, \mathrm{p}<0.001$ by $\mathrm{t}$-test) (Table 3$)$. All subscale factors of positive symptom ( $\mathrm{t}=4.78, \mathrm{p}<0.001$ by $\mathrm{t}$-test), negative symptom $(\mathrm{t}=3.07, \mathrm{p}=0.005$ by $\mathrm{t}$-test $)$, general psychopathology $(\mathrm{t}=$ 5.63, $\mathrm{p}<0.001$ by $\mathrm{t}$-test), and cognitive domain $(\mathrm{t}=5.17, \mathrm{p}<0.001$ by t-test) were significantly higher in the ECT group than in the non-ECT group. However, statistical differences were found only in general psychopathology $(t=2.11, p=0.022$ by $\mathrm{t}$-test) and cognitive domain ( $\mathrm{t}=2.14, \mathrm{p}=0.042$ by $\mathrm{t}$-test $)$ after ECT in the ECT group in comparison with the non-ECT group (Table 3).

\section{Long-term follow-ups after the index ECT}

Thirteen of fourteen patients continued to visit the hospital for follow-up after the index ECT until the end of pre-determined observation period on 31 December 2016. Six patients (46.2\%) continued ECT with the mean session number of $36.0 \pm 23.3$ in a mean period of $675.8 \pm 498.5$ days $(120-1,351$ days) after the index ECT during the observation period. The maintenance treatment of ECT continued regularly at least once every 1 to 4 weeks or intermittently whenever symptoms worsened as an acute or rescue ECT together with clozapine treatment during the observation period. The remaining seven patients (53.8\%) had treated with clozapine alone and did not have further additional ECT until the end of observation period.

Differences between patients who continued M-ECT and who did not were explored to identify clinical variables for predicting the need for M-ECT. However, demographic characteristics such as mean age, years of education, duration of illness and changes on clinical variables such as duration of clozapine administration, dose of clozapine, plasma clozapine levels, PANSS scores were not different between two groups (Table 4).

\section{Adverse events}

There was no sustained severe adverse event related to ECT

Table 2. Mean daily dose and plasma levels of clozapine in ECT and non-ECT groups in patients with clozapine-treated schizophrenia

\begin{tabular}{|c|c|c|c|c|c|c|c|c|c|}
\hline & \multicolumn{2}{|c|}{ ECT group $(\mathrm{N}=14)$} & \multirow{2}{*}{$\begin{array}{c}\text { Non-ECT } \\
\text { group }(\mathrm{N}=16)\end{array}$} & \multicolumn{2}{|c|}{ Before vs. after ECT } & \multicolumn{2}{|c|}{ Before vs. non-ECT } & \multicolumn{2}{|c|}{ After vs. non-ECT } \\
\hline & Before ECT & After ECT & & $\mathrm{t}$ & $\mathrm{p}$ & $\mathrm{t}$ & $\mathrm{p}$ & $\mathrm{t}$ & $\mathrm{p}$ \\
\hline Clozapine dose (mg) & $367.9 \pm 125.7$ & $292.9 \pm 81.1$ & $265.6 \pm 60.5$ & -1.94 & 0.074 & 2.90 & 0.007 & 1.05 & 0.302 \\
\hline P-clozapine (ng/mL) & $628.8 \pm 182.2$ & $518.2 \pm 203.1$ & $580.1 \pm 187.7$ & -2.16 & 0.049 & 0.72 & 0.478 & -0.87 & 0.393 \\
\hline
\end{tabular}

Numbers are mean \pm SD. t-tests and paired t-tests were conducted. P-clozapine: plasma clozapine, ECT: electroconvulsive therapy

Table 3. PANSS subscale factors in ECT and non-ECT groups in patients with clozapine-treated schizophrenia

\begin{tabular}{|c|c|c|c|c|c|c|c|c|c|}
\hline & \multicolumn{2}{|c|}{ ECT group $(\mathrm{N}=14)$} & \multirow{2}{*}{$\begin{array}{c}\text { Non-ECT } \\
\text { group }(\mathrm{N}=16)\end{array}$} & \multicolumn{2}{|c|}{ Before vs. after ECT } & \multicolumn{2}{|c|}{ Before vs. non-ECT } & \multicolumn{2}{|c|}{ After vs. non-ECT } \\
\hline & Before ECT & After ECT & & $\mathrm{t}$ & $\mathrm{p}$ & $\mathrm{t}$ & $\mathrm{p}$ & $\mathrm{t}$ & $\mathrm{p}$ \\
\hline \multicolumn{10}{|l|}{ Kay's } \\
\hline Total score & $101.7 \pm 13.9$ & $82.7 \pm 13.5$ & $76.6 \pm 10.1$ & -7.21 & $<0.001$ & 5.74 & $<0.001$ & 1.43 & 0.165 \\
\hline Positive symptom & $26.5 \pm 3.7$ & $19.9 \pm 4.1$ & $19.9 \pm 3.8$ & -5.68 & $<0.001$ & 4.78 & $<0.001$ & -0.01 & 0.995 \\
\hline Negative symptom & $26.4 \pm 7.6$ & $22.4 \pm 6.8$ & $20.1 \pm 3.2$ & -3.84 & 0.002 & 3.07 & 0.005 & 1.21 & 0.236 \\
\hline General psychopathology & $48.8 \pm 6.3$ & $40.4 \pm 4.2$ & $36.6 \pm 5.6$ & -6.37 & $<0.001$ & 5.63 & $<0.001$ & 2.11 & 0.022 \\
\hline \multicolumn{10}{|l|}{ Tuinier's } \\
\hline Cognitive domain & $30.1 \pm 5.7$ & $24.9 \pm 5.6$ & $21.4 \pm 3.4$ & -3.66 & 0.003 & 5.17 & $<0.001$ & 2.14 & 0.042 \\
\hline
\end{tabular}

Numbers are mean \pm SD. t-tests and paired t-tests were conducted. PANSS: Positive And Negative Syndrome Scale, ECT: electroconvulsive therapy 
Table 4. Comparison of demographic characteristics and clinical information between groups with and without maintenance ECT in patients with clozapine-resistant schizophrenia

\begin{tabular}{|c|c|c|}
\hline & $\begin{array}{c}\text { With } \\
\text { maintenance } \\
\text { ECT }(\mathrm{N}=6)\end{array}$ & $\begin{array}{c}\text { Without } \\
\text { maintenance } \\
\text { ECT }(\mathrm{N}=7)\end{array}$ \\
\hline Age (yr) & $34.3 \pm 8.2$ & $37.1 \pm 16.2$ \\
\hline Sex (male/female, $\mathrm{N}$ ) & $2 / 4$ & $5 / 2$ \\
\hline Eduction (yr) & $14.0 \pm 2.5$ & $14.3 \pm 2.1$ \\
\hline Illness duration (yr) & $14.0 \pm 8.1$ & $13.6 \pm 9.0$ \\
\hline Clozapine duration (yr) & $8.0 \pm 6.4$ & $4.8 \pm 4.0$ \\
\hline Clozapine dose before ECT (mg) & $329.2 \pm 66.0$ & $421.4 \pm 149.6$ \\
\hline Clozapine dose after ECT (mg) & $308.3 \pm 40.8$ & $292.9 \pm 105.8$ \\
\hline P-clozapine before ECT (ng/mL) & $694.0 \pm 231.4$ & $552.6 \pm 113.4$ \\
\hline P-clozapine after ECT (ng/mL) & $648.6 \pm 199.8$ & $429.3 \pm 160.2$ \\
\hline \multicolumn{3}{|l|}{ PANSS score before ECT } \\
\hline Total score & $100.5 \pm 13.4$ & $99.1 \pm 12.6$ \\
\hline Positive symptom & $26.0 \pm 3.6$ & $26.1 \pm 3.6$ \\
\hline Negative symptom & $24.8 \pm 7.8$ & $26.6 \pm 7.7$ \\
\hline General psychopathology & $49.7 \pm 5.2$ & $46.6 \pm 6.3$ \\
\hline Tuinier's cognitive domain & $28.0 \pm 5.2$ & $30.6 \pm 5.4$ \\
\hline \multicolumn{3}{|l|}{ PANSS score after ECT } \\
\hline Total score & $84.3 \pm 17.4$ & $79.4 \pm 9.9$ \\
\hline Positive symptom & $20.7 \pm 5.1$ & $18.9 \pm 3.3$ \\
\hline Negative symptom & $22.8 \pm 8.3$ & $21.4 \pm 6.2$ \\
\hline General psychopathology & $40.8 \pm 4.8$ & $39.1 \pm 3.2$ \\
\hline Tuinier's cognitive domain & $24.2 \pm 6.7$ & $25.1 \pm 5.2$ \\
\hline
\end{tabular}

Numbers are mean \pm SD. There was no difference between two groups by Mann-Whitney U test. P-clozapine: plasma clozapine, PANSS: Positive And Negative Syndrome Scale, ECT: electroconvulsive therapy

or general anesthesia, except mild postictal agitation, headache, and nausea that were successfully managed with conventional interventions and/or benzodiazepines within a few minutes or hours. The MMSE-KC scores were able to obtain in only seven patients both at the before and after index ECT among fourteen patients. The mean scores of MMSE-KC before and after the index ECT were $24.9 \pm 3.4$ and $27.4 \pm 1.8$, respectively, and there was no statistical difference. In addition, there was a significant improvement in Tuinier's cognitive domain of the PANSS ( $\mathrm{t}=-3.66$; $\mathrm{p}=0.003$; by paired $\mathrm{t}$-test) (Table 3 ).

\section{DISCUSSION}

This naturalistic observation study of the ECT effects was conducted in patients with persistent severe psychotic symptoms despite long-term clozapine treatment who could be strictly defined as clozapine-resistance excluding possible pseudo-resistance to clozapine. Including patients in our pre- vious study, ${ }^{32}$ we further investigated demographic and clinical characteristics of patients combined ECT and clozapine compared to patients treated with clozapine only, differences in psychotic symptoms responding to ECT, and the need and effectiveness for M-ECT. Individual patients were reviewed by the ad hoc committee on the indications of ECT, such as insufficient responses and intolerance to current clozapine treatment.

This study demonstrated that an acute course of ECT rapidly and substantially reduced psychotic symptoms without observable serious or adverse events in patients with clozapine-resistant schizophrenia. Of thirteen patients followed up for an average of $665.2 \pm 441.0$ days after the index ECT until the end of the pre-determined observation period, seven patients (53.8\%) maintained clozapine treatment without additional ECT.

The mean total score and all subscale factor scores of the PANSS before ECT in the ECT group were significantly higher than those in the non-ECT group, suggesting that patients with severe psychotic symptoms despite clozapine treatment tended to receive the augmentation of ECT in this study. Farooq et al. ${ }^{15}$ proposed 3 subgroups based on antipsychotic treatment response: antipsychotic-responsive, clozapine-responsive, and clozapine-resistant. Clozapine-resistance showed a suboptimal response to clozapine and had a paucity of effective intervention. In this study, the response rate by acute ECT in patients with clozapine-resistant schizophrenia was $42.9 \%$ ( 6 of 14 patients) when applying the $1-7$ scoring system based on the traditional criteria of $20 \%$ reduction in psychotic symptoms. This rate appears to be somewhat lower than the previously reported response rate of $47.4 \%$ to $72.7 \%$ in combination with clozapine and ECT. ${ }^{13,26-28}$ However, most reports did not mention the scoring system of the PANSS. ${ }^{32,51,52}$ If the 0-6 scoring system is applied to the present study, the response rate is $71.4 \%$ (10 of 14 patients). This finding obtained after excluding pseudo-resistance to clozapine supports previous reports that ECT augmentation is highly effective in patients with schizophrenia who had insufficient responses to clozapine. However, the remission rate was still limited and the response to ECT was not consistent with individual patients. In this study, the PANSS total score after acute ECT decreased to a statistically insignificant level compared with the non-ECT group, but it was not reached below the cut-off score for treatment-resistance. ${ }^{10,53}$

Most current studies ${ }^{22,32,54,55}$ have demonstrated that ECT augmentation have little or the least meaningful improvement of negative symptom as measured by the PANSS. This study showed a statistically significant decrease of negative symptom by acute ECT, but the effect size was the lowest among PANSS total and subscale factors. Taken together, the effect on 
the negative symptom from ECT in this study may not be fundamentally different from most studies in which ECT augmentation on clozapine in other races does not lead to improvement of negative symptom and/or negative type..$^{22,55,56}$ However, an extended observation period and/or more ECT sessions will be needed to determine whether improvements in negative symptoms and/or negative type can be expected with the augmentation of ECT on clozapine in patients with treatmentresistant schizophrenia.

The long-term observation of thirteen patients after acute ECT showed two clinical courses in general. Six patients (46.2\%) continued M-ECT and clozapine treatment, and the other seven (53.8\%) were treated with clozapine alone without additional ECT. This suggests that not all patients need M-ECT to maintain improved psychotic symptoms if clozapine treatment is continued after acute ECT and the relapse rate is no more than $46.2 \%$, which supports that the relapse rate is less than $63 \%$ within one month after the discontinuation of ECT as previously reported. ${ }^{26}$ The long-term observation of thirteen patients.

One of the main concerns about ECT has been the cognitive adverse events. We presented the MMSE-KC in only seven patients, at immediate before ECT and after ECT with no statistically significant difference. Although it certainly could not replace formal neuropsychological test, ${ }^{48,56,57}$ we assumed that Tuinier's cognitive domain consisting of nine items in the PANSS could provide the collateral information of the presence of cognitive impairment because it was generated from items possibly related to neuropsychological measures. ${ }^{48,56}$ And we observed that ECT augmentation improves the Tuinier's cognitive domain by the index ECT, ${ }^{35}$ otherwise at least ECT augmentation would not induce observable cognitive impairment at follow-up observation.

Several limitations to this study should be considered. First, this investigation was a naturalistic observation study that drug variables, including other psychotropic medication, were not controlled during acute ECT. Second, cognitive functions after ECT were not explored intensively with a full neurocognitive battery. Third, the long-term follow-up evaluation after ECT is needed to answer the efficacy of ECT augmentation and the need of maintenance treatment in patients with clozapineresistant schizophrenia. Despite these limitations to the interpretation and generalizability, the results in this study strongly suggest that the ECT can mobilize other mechanisms of action which could not explained the therapeutic effects of clozapine alone. ${ }^{9}$ ECT augmentation on clozapine would be a favorable option for the treatment of clozapine-resistant schizophrenia.

In conclusion, this study validated the efficacy of ECT augmentation in patients with clozapine-resistant schizophrenia with no clinically meaningful cognitive adverse events. No clin- ical predictive variables were found in this study to distinguish patients who need maintenance treatment after acute ECT to maintain clinical remission and prevent relapse. ECT augmentation on clozapine did not show sufficient effects on negative symptoms and did not reach below the cut-off scores for treatment-resistance, so that more attention should be paid to further improving the response.

\section{Acknowledgments}

This research was supported by Free Research Project (S-2015-G004100058), Dongguk University Medical Center and the Institute of Clinical Psychopharmacology, Dongguk University College of Medicine.

\section{REFERENCES}

1. Weiner RD, American Psychiatric Association Committee on Electroconvulsive Therapy. The Practice of Electroconvulsive Therapy: Recommendations for Treatment, Training, and Privileging (A Task Force Report of the American Psychiatric Association). 2nd Ed. Washington, DC: American Psychiatric Association; 2001.

2. Huuhka K, Viikki M, Tammentie T, Tuohimaa K, Björkqvist M, Alanen HM, at al. One-year follow-up after discontinuing maintenance electroconvulsive therapy. J ECT 2012;28:225-228.

3. Fink M, Sackeim HA. Convulsive therapy in schizophrenia? Schizophr Bull 1996;22:7-39.

4. Chanpattana W, Andrade C. ECT for treatment-resistant schizophrenia: a response from the far East to the UK. NICE report. J ECT 2006; 22:4-12.

5. Suzuki K, Takano T, Ebina Y, Takamatsu K, Awata S, Matsuoka H. Continuation electroconvulsive therapy to prevent relapse of schizophrenia in relapse-prone patients. J ECT 2007;23:204-205.

6. Shelef A, Mazeh D, Berger U, Baruch Y, Barak Y. Acute electroconvulsive therapy followed by maintenance electroconvulsive therapy decreases hospital re-admission rates of older patients with severe mental illness. J ECT 2015;31:125-128.

7. Biedermann F, Pfaffenberger N, Baumgartner S, Kemmler G, Fleischhacker WW, Hofer A. Combined clozapine and electroconvulsive therapy in clozapine-resistant schizophrenia: clinical and cognitive outcomes. J ECT 2011;27:e61-e62.

8. Grover S, Chakrabarti S, Hazari N, Avasthi A. Effectiveness of electroconvulsive therapy in patients with treatment resistant schizophrenia: a retrospective study. Psychiatry Res 2017;249:349-353.

9. Lin HT, Liu SK, Hsieh MH, Chien YL, Chen IM, Liao SC, et al. Impacts of electroconvulsive therapy on 1-year outcomes in patients with schizophrenia: a controlled, population-based mirror-image study. Schizophr Bull 2018;44:798-806.

10. Lee J, Takeuchi H, Fervaha G, Sin GL, Foussias G, Agid O, et al. Subtyping schizophrenia by treatment response: antipsychotic development and the central role of positive symptoms. Can J Psychiatry 2015;60: 515-522.

11. Kane J, Honigfeld G, Singer J, Meltzer H. Clozapine for the treatmentresistant schizophrenic: a double-blind comparison with chlorpromazine. Arch Gen Psychiatry 1988;45:789-796.

12. Meltzer HY, Bastani B, Kwon KY, Ramirez LF, Burnett S, Sharpe J. A prospective study of clozapine in treatment-resistant schizophrenic patients, I: preliminary report. Psychopharmacology (Berl) 1989;99(Suppl): S68-S72.

13. Havaki-Kontaxaki BJ, Ferentinos PP, Kontaxakis VP, Paplos KG, Soldatos CR. Concurrent administration of clozapine and electroconvulsive therapy in clozapine-resistant schizophrenia. Clin Neuropharmacol 2006;29:52-56.

14. Muscatello MR, Bruno A, De Fazio P, Segura-Garcia C, Pandolfo G, Zoccali R. Augmentation strategies in partial responder and/or treatment- 
resistant schizophrenia patients treated with clozapine. Expert Opin Pharmacother 2014;15:2329-2345.

15. Farooq S, Agid O, Foussias G, Remington G. Using treatment response to subtype schizophrenia: proposal for a new paradigm in classification. Schizophr Bull 2013;39:1169-1172.

16. Kerwin R. From pharmacological profiles to clinical outcomes. Int Clin Psychopharmacol 2000;15:S1-S4.

17. Remington G, Saha A, Chong SA, Shammi C. Augmentation strategies in clozapine-resistant schizophrenia. CNS Drugs 2005;19:843-872.

18. Kerwin RW, Bolonna A. Management of clozapine-resistant schizophrenia. Adv Psychiatr Treat 2005;11:101-106.

19. Porcelli S, Balzarro B, Serretti A. Clozapine resistance: augmentation strategies. Eur Neuropsychopharmacol 2012;22:165-182.

20. Miyamoto S, Jarskog LF, Fleischhacker WW. New therapeutic approaches for treatment-resistant schizophrenia: a look to the future. J Psychiatr Res 2014;58:1-6.

21. Kaster TS, Daskalakis ZJ, Blumberger DM. Clinical effectiveness and cognitive impact of electroconvulsive therapy for schizophrenia: a large retrospective study. J Clin Psychiatry 2017;78:e383-e389.

22. Petrides G, Malur C, Braga RJ, Bailine SH, Schooler NR, Malhotra AK, et al. Electroconvulsive therapy augmentation in clozapine-resistant schizophrenia: a prospective, randomized study. Am J Psychiatry 2015; 172:52-58.

23. Safferman AZ, Munne R. Combining Clozapine with ECT. Convuls Ther 1992;8:141-143.

24. Kales HC, Dequardo JR, Tandon R. Combined electroconvulsive therapy and clozapine in treatment-resistant schizophrenia. Prog Neuropsychopharmacol Biol Psychiatry 1999;23:547-556.

25. Benatov R, Sirota P, Megged S. Neuroleptic-resistant schizophrenia treated with clozapine and ECT. Convuls Ther 1996;12:117-121.

26. Kho KH, Blansjaar BA, de Vries S, Babuskova D, Zwinderman AH, Linszen DH. Electroconvulsive therapy for the treatment of clozapine nonresponders suffering from schizophrenia--an open label study. Eur Arch Psychiatry Clin Neurosci 2004;254:372-379.

27. Kupchik M, Spivak B, Mester R, Reznik I, Gonen N, Weizman A, et al. Combined electroconvulsive-clozapine therapy. Clin Neuropharmacol 2000;23:14-16.

28. Lally J, Tully J, Robertson D, Stubbs B, Gaughran F, MacCabe JH. Augmentation of clozapine with electroconvulsive therapy in treatment resistant schizophrenia: a systematic review and meta-analysis. Schizophr Res 2016;171:215-224.

29. Ahmed S, Khan AM, Mekala HM, Venigalla H, Ahmed R, Etman A, et al. Combined use of electroconvulsive therapy and antipsychotics (both clozapine and non-clozapine) in treatment resistant schizophrenia: a comparative meta-analysis. Heliyon 2017;3:e00429.

30. Masoudzadeh A, Khalilian AR. Comparative study of clozapine, electroshock and the combination of ECT with clozapine in treatment-resistant schizophrenic patients. Pak J Biol Sci 2007;10:4287-4290.

31. Grover S, Hazari N, Kate N. Combined use of clozapine and ECT: a review. Acta Neuropsychiatr 2015;27:131-142.

32. Kim HS, Kim SH, Lee NY, Youn T, Lee JH, Chung S, et al. Effectiveness of electroconvulsive therapy augmentation on clozapine-resistant schizophrenia. Psychiatry Investig 2017;14:58-62.

33. Tharyan P, Adams CE. Electroconvulsive therapy for schizophrenia. Cochrane Database Syst Rev 2005(2):CD000076.

34. Couchman L, Bowskill SV, Handley S, Patel MX, Flanagan RJ. Plasma clozapine and norclozapine in relation to prescribed dose and other factors in patients aged $<18$ years: data from a therapeutic drug monitoring service, 1994-2010. Early Interv Psychiatry 2013;7:122-130.

35. Weiner RD, Reti IM. Key updates in the clinical application of electroconvulsive therapy. Int Rev Psychiatry 2017;13:1-9.

36. Matsuda KT, Cho MC, Lin KM, Smith MW, Young AS, Adams JA. Clozapine dosage, serum levels, efficacy, and side-effect profiles: a comparison of Korean-American and Caucasian patients. Psychopharmacol Bull 1996;32:253-257.
37. Burroughs VJ, Maxey RW, Levy RA. Racial and ethnic differences in response to medicines: towards individualized pharmaceutical treatment. J Natl Med Assoc 2002;94(10 Suppl):1-26.

38. Yoshino Y, Ozaki Y, Kawasoe K, Ochi S, Niiya T, Sonobe N, et al. Combined clozapine and electroconvulsive therapy in a Japanese schizophrenia patient: a case report. Clin Psychopharmacol Neurosci 2014;12: $160-162$.

39. Trevino K, McClintock SM, Husain MM. A review of continuation electroconvulsive therapy: application, safety, and efficacy. J ECT 2010; 26:186-195.

40. Petrides G, Dhossche D, Fink M, Francis A. Continuation ECT: relapse prevention in affective disorders. Convuls Ther 1994;10:189-194.

41. Bourgon LN, Kellner CH. Relapse of depression after ECT: a review. J ECT 2000;16:19-31.

42. Suzuki K, Awata S, Matsuoka H. One-year outcome after response to ECT in middle-aged and elderly patients with intractable catatonic schizophrenia. J ECT 2004;20:99-106.

43. Shibasaki C, Takebayashi M, Fujita Y, Yamawaki S. Factors associated with the risk of relapse in schizophrenic patients after a response to electroconvulsive therapy: a retrospective study. Neuropsychiatr Dis Treat 2015;11:67-73.

44. Odeberg H, Rodriguez-Silva B, Salander P, Mårtensson B. Individualized continuation electroconvulsive therapy and medication as a bridge to relapse prevention after an index course of electroconvulsive therapy in severe mood disorders: a naturalistic 3-year cohort study. J ECT 2008;24:183-190.

45. Suzuki K, Awata S, Takano T, Ebina Y, Iwasaki H, Matsuoka H. Continuation electroconvulsive therapy for relapse prevention in middle-aged and elderly patients with intractable catatonic schizophrenia. Psychiatry Clin Neurosci 2005;59:481-489.

46. Suzuki K, Awata S, Takano T, Ebina Y, Shindo T, Harada N, et al. Adjusting the frequency of continuation and maintenance electroconvulsive therapy to prevent relapse of catatonic schizophrenia in middle-aged and elderly patients who are relapse-prone. Psychiatry Clin Neurosci 2006; 60:486-492.

47. Kay SR, Flszbein A, Opfer LA. The Positive and Negative Syndrome Scale (PANSS) for schizophrenia. Schizophr Bull 1987;13:261-276.

48. Tuinier S, Eschauzier JC, Egger JIM, Verhoeven WMA. Response and remission in schizophrenia: the limited value of new remission criteria. Clin Neuropsychiatry 2008;5:83-89.

49. Coffey CE, Lucke J, Weiner RD, Krystal AD, Aque M. Seizure threshold in electroconvulsive therapy (ECT) II. The anticonvulsant effect of ECT. Biol Psychiatry 1995;37:777-788.

50. Social Science Statistics. Available at: http://www.socscistatistics.com/ tests/Default.aspx. Accessed February 5, 2018.

51. Leucht S, Kissling W, Davis JM. The PANSS should be rescaled. Schizophr Bull 2010;36:461-462.

52. Obermeier M, Mayr A, Schennach-Wolff R, Seemüller F, Möller HJ, Riedel M. Should the PANSS be rescaled? Schizophr Bull 2010;36:455460.

53. Molins C, Roldán A, Corripio I, Isohanni M, Miettunen J, Seppälä J, et al. Response to antipsychotic drugs in treatment-resistant schizophrenia: conclusions based on systematic review. Schizophr Res 2016;178: 64-67.

54. Chanpattana W, Sackeim HA. Electroconvulsive therapy in treatmentresistant schizophrenia: prediction of response and the nature of symptomatic improvement. J ECT 2010;26:289-298.

55. Uçok A, Cakir S. Electroconvulsive therapy in first-episode schizophrenia. J ECT 2006;22:38-42.

56. Bryson G, Bell M, Greig T, Kaplan E. Internal consistency, temporal stability and neuropsychological correlates of three cognitive components of the Positive and Negative Syndrome Scale (PANSS). Schizophr Res 1999;38:27-35.

57. Nielsen RE, Lindström E, Telléus GK, Levander S. Is the PANSS cognitive scale measuring cognition? Nord J Psychiatry 2014;68:573-578. 